\title{
AÇÃO “IN VITRO” DE EXTRATOS VEGETAIS SOBRE COLLETOTRICHUM ACUTATUM, ALTERNARIA SOLANI E SCLEROTIUM ROLFSII
}

\section{R.J. Domingues ${ }^{1}$, J.D.F. de Souza ${ }^{2}$, J.G. Töfoli ${ }^{1}$, D.R. Matheus ${ }^{3}$}

${ }^{1}$ Instituto Biológico, Centro de Pesquisa e Desenvolvimento de Sanidade Vegetal, Av. Cons. Rodrigues Alves, 1252, CEP 04014-002, São Paulo, SP, Brasil. E-mail: domingues@biologico.sp.gov.br

\section{RESUMO}

\begin{abstract}
A utilização de fungicidas é, em muitos casos, a única medida eficiente e viável de controlar doenças e garantir a sustentabilidade da atividade agrícola. Por outro lado, é também uma tecnologia que traz impactos negativos ao ambiente e à saúde pública. Os fungos Alternaria solani e Colletotrichum acutatumcausam graves prejuízos às culturas de tomate e morango, respectivamente. Sclerotium rolfsii é considerado como patógeno polífago, capaz de provocar danos severos a diversas espécies agrícolas de importância econômica. O presente trabalho teve como objetivo avaliar a ação de extratos etanólicos e hexânicos de oito espécies vegetais sobre: a) inibição de crescimento micelial desses fitopatógenos, b) inibição da germinação de conídios (A. solanie C. acutatum) e c) inibição da germinação de escleródios de $S$. rolfsii. Os extratos hexânicos de Ruta graveolens, Allamanda cathartica, Impatiens walleriana, Allium sativum e Lavandula augustifolia foram os que proporcionaram os menores valores de crescimento micelial dos três patógenos. $O$ extrato hexânico de A. sativum foi o único a inibir totalmente a germinação de conídios de A. solani. Os extratos hexânicos de I. walleriana, A. sativume L. augustifolia foram os únicos em que se verificou ausência total de germinação de conídios de C. acutatum. Os extratos hexânicos de R. graveolens e de I. walleriana inibiram totalmente a germinação de escleródios de $S$. rolfsii.
\end{abstract}

PALAVRAS-CHAVE: Controle alternativo, antracnose, pinta preta, podridão de Sclerotium.

\begin{abstract}
IN-VITRO ACTION OF PLANTEXTRACTSONCOLLETOTRICHUM ACUTATUM,ALTERNARIA SOLANI ANDSCLEROTIUM ROLFSII.The use of fungicides is, in many cases, the only efficient and viable measure for controlling diseases and guaranteeing the sustainability of agricultural activity. On the other hand, it is also a technology that brings negative impacts to the environment and public health. The fungi Anternaria solani and Colletotrichum acutatum cause serious damages to the tomato and strawberry productions, respectively. Sclerotium rolfsii is a soil pathogen, capable of provoking severe damages to several agricultural species. The present work was aimed at evaluating the action of ethanolic and hexanic extracts of 8 vegetable species on the: a) inhibition of the mycelial growth of these phytopathogens, $b$ ) inhibition of the conidial germination (A. solani and C. acutatum) and c) inhibition of the sclerotial germination of $S$. rolfsii. The hexanic extracts of Ruta graveolens, Allamanda cathartica, Impatiens walleriana, Allium sativum and Lavandula augustifolia were the ones that provided the smallest values of mycelial growth of the 3 pathogens. The hexanic extract of $A$. sativum was the only one that inhibited the conidial germination of A. solani. The hexanic extracts of I. walleriana, A. sativum and L. augustifolia were the only ones that led to the total absence of conidial germination of C.acutatum. The hexanic extracts of R.graveolens and I. walleriana totally inhibited the sclerotial germination of $S$. rolfsii.
\end{abstract}

KEY WORDS: Alternative control, anthracnose, early blight, Sclerotium root rot.

\section{INTRODUÇÃO}

Ao mesmo tempo em que representa uma solução eficiente e econômica para a agricultura(KIMATI,1995), o controle químico de doenças é também considerado uma tecnologia que traz impactos negativos ao meio ambiente e à saúde pública (BETTIOL, 1997) como: geração de produtos de degradação ou metabólitos,

\footnotetext{
${ }^{2}$ Instituto Biológico, Centro de P\&D de Sanidade Animal, São Paulo, SP, Brasil

${ }^{3}$ Instituto de Botânica, Seção de Micologia e Liquenologia, São Paulo, SP, Brasil
} 
persistência de produtos no meio ambiente (meia vida), resíduos acima dos limites de tolerância em alimentos (AzEvedo, 2003; ZAmbolim et al., 2000), além de intoxicação de agricultores, eliminação dos microorganismos responsáveis pela degradação de matéria orgânica e por controle biológico (SCHWAN-ESTRADA et al., 2003).

Segundo Harbourne (1994), a diversidade bioquímica das plantas é tão rica quanto à dos animais. Diversas moléculas complexas como terpenoides, alcaloides e compostos fenólicos são sintetizados pelo chamado metabolismo secundário das plantas e são de grande importância nas relações ecológicas planta/planta, planta/animal e, inclusive, planta/ micro-organismo fitopatogênico. O mesmo autor destaca que a riqueza de seu metabolismo se explica pelo fato de que as plantas estão enraizadas no solo onde vivem, não podendo reagir como os animais às adversidades do ambiente. Trata-se de uma alternativa viável como fonte de substâncias menos tóxicas e cujo potencial de ação contra fitopatógenos já pôde ser comprovado por vários autores (BONALDO et al., 2004; Miguel et al., 2006; Pinto et al., 1998; VAlarini et al., 1994).

Alternaria solani (ELL. \& Martin) Jones \& Grout, Colletotrichum acutatum Simmonds e Sclerotium rolfsii Sacc. são fungos fitopatogênicos capazes de provocar danos severos a várias espécies agrícolas de importância econômica.

A. solani, agente causal da doença conhecida como "pinta preta", está entre os principais patógenos em folhas, hastes e frutos do tomateiro (TELlo MARQuinA; DE LA VEGA, 1995). A alta severidade da "pinta preta" é caracterizada por intensa redução da área foliar e vigor das plantas, quebra de hastes, queda e depreciação de frutos, bem como a morte de plantas (VALE et al., 2000; Kurozawa; Pavan, 2005). Afeta a produtividade equalidade de frutos, ocasionando, via de regra, perdas elevadas quando medidas de controle não são conduzidas de forma adequada (Lopes; Ávila, 2005; Jones et al., 1993). Estudo realizado por BAsU (1974) demonstrou que a doença, sem a aplicação de fungicidas, pode atingir até $60 \%$ da área foliar causando reduções de $10 \%$ no tamanho dos frutos e 10 a $30 \%$ no número de frutos comerciais.

A antracnose ou flor preta é considerada a principal doença da cultura do morangueiro (PAssos, 1999), podendo causar perdas que variam entre 30 e $68 \%$ (Henz et al., 1992). A doença é causada pelo fungo $C$. acutatum, embora $C$. fragariae possa, em pequena escala, produzir sintomas em flores (TANAKA; PAsSOS, 1998). C. acutatum pode infectar, além das flores, frutos, pedúnculos, folhas, meristemas apicais e parte superior do rizoma e é de difícil controle, podendo ser limitante quando as condições climáticas forem favoráveis (TANAKA et al., 2005).
S. rolfsii é um fungo que faz parte da microflora do solo (habitante do solo) e é considerado como um patógeno causador de podridão de raiz e colo, podendo atacar plantas em todos os seus estádios de desenvolvimento. Os danos provocados às raízes comprometem a absorção de água e nutrientes, prejudicando o desenvolvimento das plantas. As plantas mais jovens normalmentesão mais sensíveis, podendo morrer rapidamente, enquanto as mais velhas demoram mais ou até mesmo nem chegam a morrer, mas tem a sua produtividade reduzida (BEDENDO, 1995). O micélio dá origem aos escleródios, inicialmente pequenos, de cor brancaque, duranteoseu desenvolvimento, escurecem podendo ser esféricos ou de formato irregular, responsáveis pela sobrevivência a condições adversas e disseminação do fungo (BEDENDO, 1995; AGRIOS, 1997).

Diante do exposto, o presente trabalho foi realizado com o objetivo de verificar o efeito de extratos etanólicos ehexânicos de plantas exóticas comerciais sobre o crescimento micelial dos três fungos fitopatogêncios já citados, na germinação de conídios de $C$. acutatum e de $A$. solani e na germinação de escleródios de $S$. rolfsii.

\section{MATERIAL E MÉTODOS}

\section{Preparo dos extratos}

Para o preparo dos extratos hexânicos e etanólicos foram utilizadas folhas de Hibiscus rosa-sinensis, Allamanda cathartica, Coffea arabica, Ruta graveolens, Lavandula augustifolia, Ricinus communis, Impatiens walleriana e bulbilhos de Allium sativum. O material vegetal coletado foi seco em estufa a $40^{\circ} \mathrm{C}$ e posteriormente moído. O pó resultante foi submetidoà extração com etanol e hexano, à temperatura ambiente, por 3 dias. Os solventes foram filtrados e evaporados em um evaporador à pressão reduzida. Os resíduos hexânicos e etanólicos foram depositados na extratoteca do Laboratório de Fungicidas e Fitoprotetores, do Instituto Biológico/SAA, SP, e utilizados para os testes.

Efeito de extratos vegetais sobre o crescimento micelial dos fungos fitopatogênicos

Um experimento preliminar foi realizado com todos os extratos em meio de cultura BDA (batatadextrose-ágar) que foi preparado e autoclavado por 30 min a $120^{\circ} \mathrm{C}$. Cada um dos extratos foi adicionado ao BDA fundente $\left( \pm 60^{\circ} \mathrm{C}\right)$ nas concentrações de 0 e 1.000 $\mu \mathrm{g} / \mathrm{mL}$ e vertido em placas de Petri $(5 \mathrm{~cm} \varnothing)$. Discos de $5 \mathrm{~mm}$ de diâmetro, contendo micélio dos fungos, foram transferidos para o centro das placas que foram em seguida incubadas a $25^{\circ} \mathrm{C}$ em ausência de luz. 
A avaliação foi realizada quando as parcelas testemunhas foram completamente tomadas pelos fungos, medindo-se o crescimento radial em duas retas perpendiculares traçadas no fundo de cada placa.

Os cinco extratos que promoveram maior inibição do crescimento foram avaliados em experimentos subsequentes nas concentrações $0,1,10,100,1.000 \mathrm{e}$, para A. solanie C. acutatum, até $10.000 \mu \mathrm{g} / \mathrm{mL}$, empregando-se a mesma metodologia agora os incubando em placas de Petri de $9 \mathrm{~cm}$ de diâmetro.

Efeito de extratos vegetais sobre a germinação de conídios de C. acutatum e A. solani

Para o experimento de inibição da germinação de conídios, foi utilizado o método do celofane descrito por Nelly (1978). Dez discos de papel celofane de 0,8 $\mathrm{cm}$ de diâmetro foram colocados em placas de Petri sobre 3 discos de papel de filtro embebidos em solução de extratos nas concentrações 0 e $1.000 \mu \mathrm{g} / \mathrm{mL}$, em triplicata. Posteriormente, uma gota de suspensão de conídios de A. solani, e C. acutatum, na concentração de $10^{4}$ conídios/mL foi depositada sobre cada disco de celofane. As placas assim preparadas foram mantidas sob fotoperíodo de $12 \mathrm{~h} \mathrm{e} 25^{\circ} \mathrm{C}$.
A avaliação de germinação dos conídios foi feita transferindo-se os discos de celofane para uma lâmina de vidro, com o auxílio de uma pinça, sobre a qual foram colocadas uma gota de água e uma lamínula. A observação foi feita em microscópio óptico após 16h de incubação considerando-se como germinados os conídios que já apresentassem tubo germinativo ou em início de formação. O delineamento experimental utilizado foi inteiramente casualizado com 4 repetições, sendo que cada parcela consistiu de 1 placa de Petri com 5 discos de celofane.

\section{Efeito de extratos vegetais sobre a germinação de escleródios de $S$. rolfsi.}

Dez escleródios de $S$. rolfsii foram inoculados em placas de Petri $(5 \mathrm{~cm} \varnothing)$ contendo meio de cultura BDA e cada um dos extratos, preparadas de forma semelhante ao experimento de inibição do crescimento micelial já descrito e incubadas por $48 \mathrm{~h}$ a $24^{\circ} \mathrm{C}$ e fotoperíodo de $12 \mathrm{~h}$. O delineamento experimental foi inteiramente casualizado com cada parcela sendo composta por 5 placas de cada extrato contendo 10 escleródios cada uma. A avaliação foi feita contando-se a porcentagem de escleródios germinados.

Tabela 1 - Crescimento micelial (diâmetro médio em cm e porcentagem de inibição em relação à testemunha) de S. rolfsii, C. acutatum e A. solani em placas de Petri de $5 \mathrm{~cm}$ de diâmetro, contendo meio de cultura BDA + extratos vegetais na concentração de $1.000 \mu \mathrm{g} / \mathrm{mL}$.

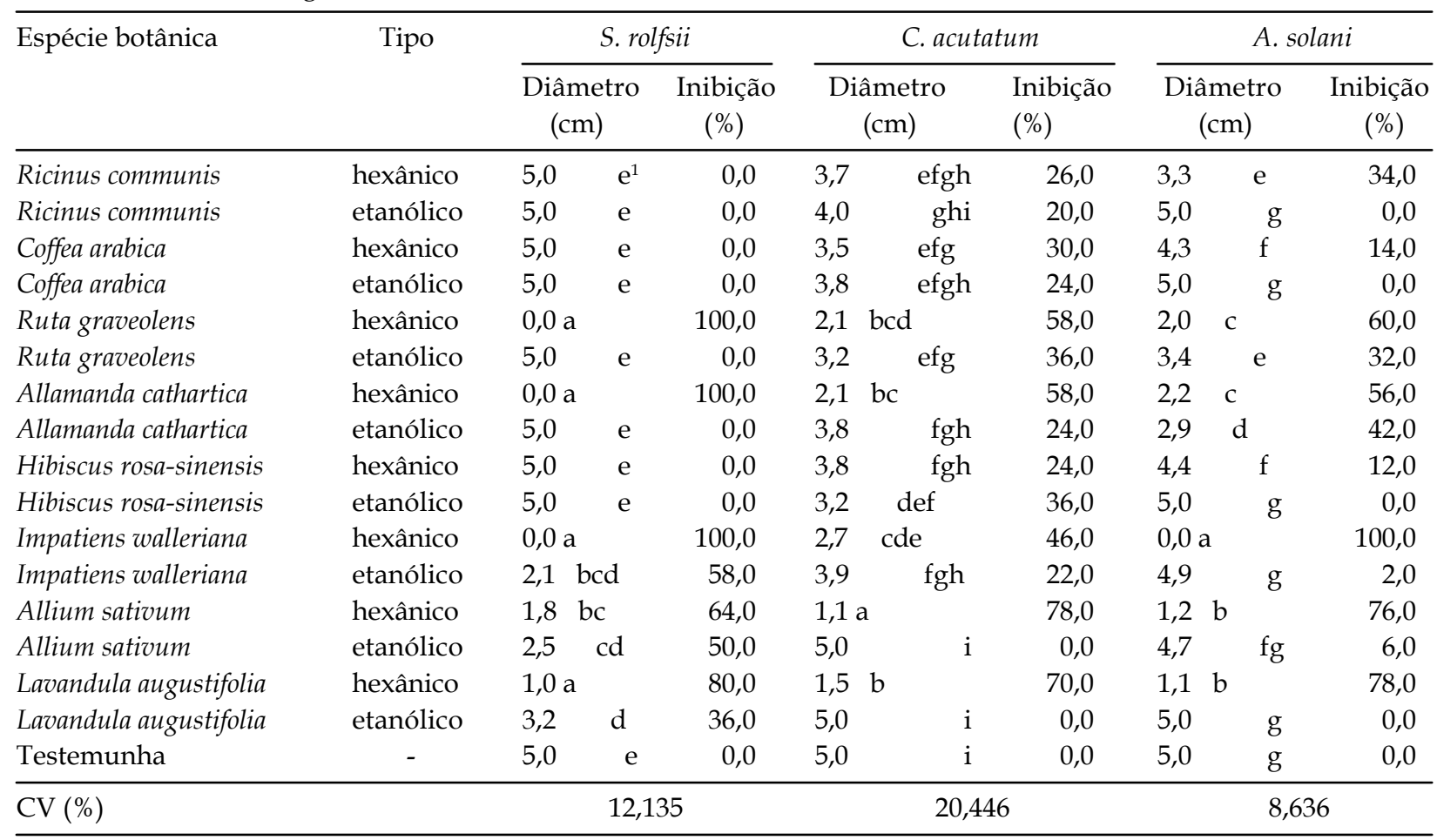

${ }^{1}$ Médias seguidas de mesma letra nas colunas não diferem entre si pelo teste de Tukey a 5 \% de probabilidade. 
Em todos os experimentos, tratamentos contendo hexano e etanol foram utilizados como controle negativo.

\section{RESULTADOS E DISCUSSÃO}

Os resultados do ensaio preliminar de crescimento micelial para os fitopatógenos estão apresentados na Tabela 1. Em geral, os melhores resultados foram obtidos com os extratos hexânicos em relação aos etanólicos. Os extratos hexânicos de $R$. graveolens, $A$. cathartica, I. walleriana, A. sativum eL. augustifoliaforam os que proporcionaram os menores valores de crescimento. Inibição total do crescimento micelial foi obtida com os extratos de R. graveolens, A. cathartica, I. walleriana para S. rolfsii e com I. walleriana para A. solani. Nenhum extrato conseguiu inibir totalmente o crescimento de C. acutatum.

Quando foram comparados apenas a ação dos melhores extratos sobre o crescimento micelial de $S$. rolfsii (Tabela 2), apenas $R$. graveolens e I. walleriana conseguiram inibir totalmente o crescimento do fun- go a $1.000 \mu \mathrm{g} / \mathrm{mL}$. R. graveolens foi o que mais se destacou na concentração de $100 \mu \mathrm{g} / \mathrm{mL}$. A $10 \mu \mathrm{g} /$ $\mathrm{mL}$, proporcionou resultado semelhante aI.walleriana, sendo estatisticamente diferente dos demais tratamentos. Nenhum dos extratos inibiu significativamente o crescimento micelial deS. rolfsiina concentração de $1 \mu \mathrm{g} / \mathrm{mL}$.

Com relação a C. acutatum (Tabela 3), verificou-se inibição total do crescimento micelial para os cinco melhores extratos quando testados na concentração de $10.000 \mu \mathrm{g} / \mathrm{mL}$.A $1.000 \mu \mathrm{g} / \mathrm{mL}$, R. graveolens foi o extrato no qual o patógeno conseguiu crescer menos. $R$ graveolens não diferiu estatisticamente deI.walleriana e A. sativum na concentração de $100 \mu \mathrm{g} / \mathrm{mL}$ e apenas de A. sativum a $10 \mu \mathrm{g} / \mathrm{mL}$.

Para A. solani (Tabela 4), os cinco extratos selecionados inibiram totalmente o seu crescimento micelial na concentração de $10.000 \mu \mathrm{g} / \mathrm{mL}$. R. graveolens não diferiu estatisticamente de A.cathartica e deA.sativum a $1.000 \mu \mathrm{g} / \mathrm{mL}$. A $100 \mu \mathrm{g} / \mathrm{mL}$, A. sativum foi superior a R. graveolens e I. walleriana, sendo semelhante a $A$. cathartica e L. augustofolia. O patógeno não foi inibido por nenhum extrato na concentração de $10 \mu \mathrm{g} / \mathrm{mL}$.

Tabela 2 - Crescimento micelial (diâmetro médio em cm) de S. rolfsii em placas de Petri de 9,0 cm de diâmetro, contendo meio de cultura BDA + extratos vegetais hexânicos nas concentrações de 1, 10, 100 e $1.000 \mu \mathrm{g} / \mathrm{mL}$.

\begin{tabular}{lcccc}
\hline Espécie botânica & \multicolumn{4}{c}{ Concentrações dos extratos } \\
\cline { 2 - 5 } & $1 \mu \mathrm{g} / \mathrm{mL}$ & $10 \mu \mathrm{g} / \mathrm{mL}$ & $100 \mu \mathrm{g} / \mathrm{mL}$ & $1.000 \mu \mathrm{g} / \mathrm{mL}$ \\
\hline Ruta graveolens & 9,0 & $4,6 \mathrm{~d}$ & $2,5 \mathrm{~d}$ & $0,0 \mathrm{~d}$ \\
Allamanda cathartica & 9,0 & $8,3 \mathrm{ab}$ & $5,4 \mathrm{~b}$ & $2,3 \mathrm{bc}$ \\
Impatiens walleriana & 9,0 & $4,6 \mathrm{~d}$ & $3,8 \mathrm{c}$ & 0,0 \\
Allium sativum & 9,0 & $7,3 \mathrm{~b}$ & $5,5 \mathrm{~b}$ & $2,7 \mathrm{~b}$ \\
Lavandula augustifolia & 9,0 & $5,9 \mathrm{c}$ & $3,8 \mathrm{c}$ & $\mathrm{c}$ \\
Testemunha & 9,0 & $9,0 \mathrm{a}$ & $9,0 \mathrm{a}$ & $9,0 \mathrm{a}$ \\
\hline CV (\%) & 7,934 & 6,701 & 4,873 & 9,325 \\
\hline
\end{tabular}

${ }^{1}$ Médias seguidas de mesma letra nas colunas não diferem entre si pelo teste de Tukey a 5 \% de probabilidade.

Tabela 3 - Crescimento micelial (diâmetro médio em $\mathrm{cm}$ ) de C. acutatum em placas de Petri de 9,0 cm de diâmetro, contendo meio de cultura BDA + extratos vegetais hexânicos nas concentrações de 0, 10, 100,1.000 e $10.000 \mu \mathrm{g} / \mathrm{mL}$.

\begin{tabular}{lcccc}
\hline Espécie botânica & \multicolumn{4}{c}{ Concentrações dos extratos } \\
\cline { 2 - 5 } & $10 \mu \mathrm{g} / \mathrm{mL}$ & $100 \mu \mathrm{g} / \mathrm{mL}$ & $1.000 \mu \mathrm{g} / \mathrm{mL}$ & $10.000 \mu \mathrm{g} / \mathrm{mL}$ \\
\hline Ruta graveolens & $8,3 \mathrm{~B}$ & $6,5 \mathrm{e}$ & $4,0 \mathrm{~d}$ & 0,0 \\
Allamanda cathartica & $9,0 \mathrm{~A}$ & $7,9 \mathrm{~b}$ & $5,0 \mathrm{c}$ & 0,0 \\
Impatiens walleriana & $9,0 \mathrm{~A}$ & $7,0 \mathrm{de}$ & $6,3 \mathrm{~b}$ & 0,0 \\
Allium sativum & $8,2 \mathrm{~B}$ & $7,1 \mathrm{cde}$ & $5,7 \mathrm{bc}$ & 0,0 \\
Lavandula augustifolia & $9,0 \mathrm{~A}$ & $7,7 \mathrm{bcd}$ & $5,9 \mathrm{~b}$ & 0,0 \\
Testemunha & $9,0 \mathrm{~A}$ & $9,0 \mathrm{a}$ & $9,0 \mathrm{a}$ & 9,0 \\
\hline $\mathrm{CV}(\%)$ & 1,832 & 3,911 & 4,437 & - \\
\hline
\end{tabular}

${ }^{1}$ Médias seguidas de mesma letra nas colunas não diferem entre si pelo teste de Tukey a 5 \% de probabilidade. 
Em relação à germinação de escleródios deS. rolfsii e de conídios de A. solani e de C. acutatum (Tabela 6), verificou-se a mesma tendência de superioridade dos extratos hexânicos sobre os etanólicos, com exceção de $R$. communis e de L. augustifolia, cujos extratos etanólicos proporcionaram menores porcentagens de germinação que os hexânicos.

O extrato hexânico de $A$. sativum foi o único a inibir totalmente a germinação de conídios de A. solani. Os extratos de R.communis(etanólico), L.augustifolia(etanólico e hexânico) e I. walleriana (hexânico) reduziram a germinação de conídios quando comparados à testemunha.

Em relação a C. acutatum, enquanto alguns extratos reduziram, outros foram indiferentes ou até mesmo induziram a germinação de conídios quando comparados com os valores obtidos na testemunha. Os extratos hexânicos deI. walleriana, A. sativum eL.augustifolia foram os únicos em que verificou-se ausência total de germinação. Para os extratos de C. arabica (etanólico), R. graveolens (hexânico) e A. cathartica (hexânico), verificou-se níveis de germinação inferiores aos verificados na testemunha. Os extratos de $R$. communis (hexânico etanólico), C.arábica (hexânico), R.graveolens (etanólico), H. rosa-sinensis (etanólico) e I. walleriana (etanóico) induziram a germinação de conídios enquanto A. cathartica (etanólico), H. rosa-sinensis (hexânico), A. sativum (etanólico) e L. augustifolia (etanólico) foram semelhantes à testemunha.

Tabela 4 - Crescimento micelial (diâmetro médio em cm) de $A$. solaniem placas de Petri de $9,0 \mathrm{~cm}$ de diâmetro, contendo meio de cultura BDA + extratos vegetais hexânicos nas concentrações de 10, 100, 1.000 e 10.000 g. $\mathrm{mL}$.

\begin{tabular}{lcccc}
\hline Espécie botânica & \multicolumn{4}{c}{ Concentrações dos extratos } \\
\cline { 2 - 5 } & $10 \mu \mathrm{g} / \mathrm{mL}$ & $100 \mu \mathrm{g} / \mathrm{mL}$ & $1.000 \mu \mathrm{g} / \mathrm{mL}$ & $10.000 \mu \mathrm{g} / \mathrm{mL}$ \\
\hline Ruta graveolens & 9,0 & $7,0 \mathrm{~b}$ & $3,2 \mathrm{c}$ & 0,0 \\
Allamanda cathartica & 9,0 & $5,8 \mathrm{bc}$ & $3,9 \mathrm{bc}$ & 0,0 \\
Impatiens walleriana & 9,0 & $6,8 \mathrm{~b}$ & $4,8 \mathrm{~b}$ & 0,0 \\
Allium sativum & 9,0 & $5,3 \mathrm{c}$ & $4,5 \mathrm{bc}$ & 0,0 \\
Lavandula augustifolia & 9,0 & $6,3 \mathrm{bc}$ & $4,7 \mathrm{~b}$ & 0,0 \\
Testemunha & 9,0 & $9,0 \mathrm{a}$ & $9,0 \mathrm{a}$ & 9,0 \\
\hline CV (\%) & 6,984 & 9,001 & \\
\hline
\end{tabular}

${ }^{1}$ Médias seguidas de mesma letra nas colunas não diferem entre si pelo teste de Tukey a $5 \%$ de probabilidade.

Tabela 5 - Porcentagem de germinação de conídios de A. solani e C. acutatume de escleródios de S. rolfsii em placas de Petri de $5 \mathrm{~cm}$ de diâmetro, contendo meio de cultura BDA + extratos vegetais na concentração de $1.000 \mu \mathrm{g} / \mathrm{mL}$.

\begin{tabular}{|c|c|c|c|c|c|}
\hline Espécie botânica & Tipo & A. solani & \multicolumn{2}{|c|}{ C. acutatum } & S. rolfsii \\
\hline Ricinus communis & hexânico & $87,8 \mathrm{ab}$ & \multicolumn{2}{|c|}{$92,0 \mathrm{a}$} & $100,0 \mathrm{a}$ \\
\hline Ricinus communis & etanólico & $25,7 \quad d$ & \multicolumn{2}{|c|}{$71,7 \quad b$} & $100,0 \mathrm{a}$ \\
\hline Coffea arabica & hexânico & $100,0 \mathrm{a}$ & \multicolumn{2}{|c|}{$93,4 \mathrm{a}$} & $100,0 \mathrm{a}$ \\
\hline Coffea arabica & etanólico & $100,0 \mathrm{a}$ & 18,7 & gh & $100,0 \mathrm{a}$ \\
\hline Ruta graveolens & hexânico & $98,9 \mathrm{a}$ & 12,1 & hi & 0,0 \\
\hline Ruta graveolens & etanólico & $100,0 \mathrm{a}$ & 54,3 & $\mathrm{C}$ & $96,0 \mathrm{a}$ \\
\hline Allamanda cathartica & hexânico & $93,6 \mathrm{ab}$ & 11,5 & \multirow{2}{*}{$\mathrm{fg}^{\mathrm{i}}$} & $94,0 \mathrm{a}$ \\
\hline Allamanda cathartica & etanólico & $100,0 \mathrm{a}$ & 21,1 & & $93,0 \mathrm{ab}$ \\
\hline Hibiscus rosa-sinensis & hexânico & $100,0 \mathrm{a}$ & 32,3 & $\mathrm{e}$ & $31,0 \quad c$ \\
\hline Hibiscus rosa-sinensis & etanólico & $100,0 \mathrm{a}$ & 41,3 & $\mathrm{~d}$ & $100,0 \mathrm{a}$ \\
\hline Impatiens walleriana & hexânico & $62,1 \quad c$ & 0,0 & $\mathrm{j}$ & 0,0 \\
\hline Impatiens walleriana & etanólico & $100,0 \mathrm{a}$ & 54,8 & c & $100,0 \mathrm{a}$ \\
\hline Allium sativum & hexânico & 0,0 & 0,0 & $\mathrm{j}$ & $6,0 \quad d$ \\
\hline Allium sativum & etanólico & $100,0 \mathrm{a}$ & 25,4 & efg & $94,0 \mathrm{a}$ \\
\hline Lavandula augustifolia & hexânico & $79,3 \mathrm{~b}$ & 0,0 & $\mathrm{j}$ & $80,0 \quad b$ \\
\hline Lavandula augustifolia & etanólico & $37,3 \quad d$ & 29,6 & $\mathrm{e}$ & $100,0 \mathrm{a}$ \\
\hline Testemunha & - & $100,0 \mathrm{a}$ & 28,1 & ef & $100,0 \mathrm{a}$ \\
\hline$\overline{\mathrm{CV}(\%)}$ & & 5,885 & \multicolumn{2}{|l|}{6,923} & 11,567 \\
\hline
\end{tabular}

${ }^{1}$ Médias seguidas de mesma letra nas colunas não diferem entre si pelo teste de Tukey a 5 \% de probabilidade. 
Os extratos hexânicos de $R$. graveolens e de $I$. walleriana inibiram totalmente a germinação de escleródios de $S$. rolfsii, sendo semelhantes ao extrato hexânico de A. sativum. Os extratos hexânicos de $H$. rosa-sinensis e de L. augustifolia proporcionaram valores intermediários de porcentagem de germinação.

A ação de óleos essenciais e extratos de alho e arruda sobre fitopatógenos já foi amplamente relatada na literatura. BOLKAN; RIBEIRO (1981) verificaram a toxicidade de extrato de alho sobreFusariummonilforme e Rhizoctonia solani. O extrato de óleo foi tóxico para Curvularia spp., Alternaria spp. (BARros et al., 1995) e Colletotrichum gloeosporiodes (RIBEIRO; BEDENDO, 1999). O óleo essencial de alho, empregado por CHALFOUN; Carvalho (1987) inibiu o crescimento micelial de Gibberella zeae, Alternaria zinniae e Macrophomina phaseolina. BERNARDOet al. (1998) relataram inibição de $100 \%$ na germinação de conídios de C. graminicola com óleo essencial de R. graveolens. MARCANo et al. (2005) verificaram superioridade do extrato aquoso de $A$. satioum sobre o de $R$. comunis na inibição do crescimento micelial deS. rolfsii e Thielaviopsisbasicola em meio de batata + dextrose + agar, embora ambos tenham diferido significativamente da testemunha.

Em geral os extratos hexânicos mostraram maior atividade antifúngica em relação aos seus correspondentes etanólicos. Sabe-se que os extratos brutos na verdade são constituídos não de uma, mas de diversas substâncias quejuntas podem ser as responsáveis pela ação fungitóxica. Provavelmente, essas substâncias produzidas pelas espécies vegetais estudadas foram melhor extraídas pelo hexâno (solventeapolar) do que pelo etanol (solvente polar). Segundo TROMBETA et al. (2005), acredita-se que os óleos constituídos de monoterpenos possuam esta atividade por desencadearem efeitos tóxicos na estrutura e na função das membranas das células dos micro-organismos como, por exemplo, alterações na fluidez e permeabilidade einteração com componentes internos da célula, ações estas explicadas principalmente pelo caráter lipofílico dessas substâncias.

O efeito da indução da germinação de conídios de C. acutatum foi verificado por BonAldo; PAscholati (2007) em C. sublineolum e C. lagenarium e pode ser explicado pela presença de substâncias estimuladoras nos extratos, pela disponibilização de nutrientes ou pela inativação da micosporina-alanina, um autoinibidor de germinação já encontrado na mucilagem que envolve os conídios de outras espécies do gênero Colletotrichum.

Em geral, os trabalhos que estudam ação antimicrobiana de extratos são feitos empregando-se espécies conhecidas como plantas medicinais, apresentando grande quantidade de relatos que comprovam sua eficácia na medicina humana. No presente trabalho foram utilizadas espécies que possuem pou- ca ou nenhuma utilização desse tipo, exceto para $A$. sativum, $R$. communis e $R$. graveolens. Tal fato mostra quão amplo pode ser este campo de pesquisa equanto ainda existe por ser feito. Diversas espécies vegetais podem apresentar potencial como fontes alternativas de substâncias com ação fungicida e o seu estudo poderá contribuir para a redução dos problemas hoje existentes no controle químico de doenças fúngicas na agricultura. É evidente que outros estudos devem ser realizados visando avaliar, também, o potencial toxicológico dessas substâncias ao homem e ao ambiente antes de serem empregadas em larga escala.

\section{REFERÊNCIAS}

AGRIOS, G.N. Plant pathology. San Diego: Academic Press, 1997. 635p.

AZEVEDO, L.A.S. Fungicidas protetores: fundamentos para o uso racional. Campinas: EMOPI Editora e Gráfica, 2003.320p.

BARROS, S.T.; OLIVEIRA, N.T.; MAIA, L.C. Efeito do extrato de alho (Allium sativum) sobre o crescimento micelial e germinação de conídios de Curvularia spp. e Alternaria spp. Summa Phytopathologica, v.21, n.2, p.168170, 1995.

BASU, P.K. Measuring early blight, its progress and influence on fruit losses in nine tomato cultivars. Canadian Plant Diseases, v.54, p.45-51, 1974.

BEDENDO, I. P. Grupos de doenças. In: BERGAMIN FILHO, A.; KIMATI, H.; AMORIN, L. (Ed.). Manual de fitopatologia: princípios e conceitos. 3.ed. São Paulo: Ceres, 1995. v.1, p.805-907.

BERNARDO, R; SCHWAN-ESTRADA, K.R.F.; STANGARLIN, J.R.; CRUZ, M.E.S.; PASCHOLATI, S.F. Fungitoxicidade de alguns óleos essenciais contra fungos fitopatogênicos. Fitopatologia Brasileira, v.23, p.227, 1998. Suplemento. Trabalho apresentado no CONGRESSO BRASILEIRO DE FITOPATOLOGIA, 31., 1998, Fortaleza,CE. Resumos. Fortaleza, 1998.

BETTIOL, W. Alguns produtos alternativos para o controle de doenças de plantas em agricultura orgânica. In: CICLO DE PALESTRAS SOBRE AGRICULTURA ORGÂNICA, 2., 1997, São Paulo, SP. Resumos. São Paulo, 1997. p.52-63.

BOLKAN, H.A.; RIBEIRO, W.R.C. Efeito do extrato de alho em Cylindrocladium clavatum, Fusarium moniliforme var. subglutinan e Rhizoctonia solani. Fitopatologia Brasileira, v.6, n.1, p.565-566, 1981

BONALDO, S. M.; SCHWAN-ESTRADA, K. R. F.; STANGARLIN, J. R.; TESSMANN, D. J.; SCAPIM, C. A. Fungitoxicidade, atividade elicitora de fitoalexinas e 
proteção de pepino contra Colletotrichum lagenarium, pelo extrato aquoso de Eucalyptus citriodora. Fitopatologia Brasileira, v.29, n.2, p.128-134, 2004.

BONALDO, S.M.; PASCHOLATI, S.F. Efeito de frações purificadas de Saccharomyces cerevisiae na germinação de conídios e formação de apressórios por Colletotrichum sublineolum e Colletotrichum lagenarium. Summa Phytopathologica, v.33, n.3, p.233-238, 2007.

CHALFOUN, S.M.; CARVALHO, V.D. Efeito do extrato e de óleo industrial sobre o desenvolvimento de fungos. Fitopatologia Brasileira, v.12, n.3, p.234-235, 1987.

HARBOURNE, J.B. The plant and its biochemical adaptation to the environment. New York: Academic Press, 1994. 384p.

HENZ, G.P.; BOITEUX, L.S.; LOPES, C.A. Outbreak of strawberry anthracnose caused by Colletotrichum acutatum in central Brazil. Plant Disease, v.76, n.2, p.212, 1992.

JONES, J.B.; STALL, R.E.; ZITTER, T.A. Compedium of tomato diseases. St. Paul: APS, 1993. 73p.

KIMATI, H. Controle químico. In: BERGAMIN FILHO, A; KIMATI, H; AMORIN, L. (Ed.). Manual de fitopatologia - princípios e conceitos. São Paulo: Agronômica Ceres, 1995. v.1, p.761-785.

KUROZAWA, C.; PAVAN, M. Doenças do Tomateiro. In: KIMATI, H; AMORIN, L.; RESENDE, J.A.M. BERGAMIN FILHO, A; CAMARGO, L.E.A. (Ed.) manual de fitopatologia - doenças das plantas cultivadas. São Paulo: Agronômica Ceres, 2005. v.2, p.607-626.

LOPES, C.A.; ÁVILA, A.C. Doenças do tomateiro. Brasília: Embrapa Hortaliças, 2005. 151p.

MARCANO, D.A.; VARGAS, N.; PIRE, A. Efecto de extratos vegetales y fungicidas sintéticos sobre el crescimiento in vitro de Sclerotium rolfsii y Thielaviopsis basicola. Caracas. Revista de la Facultad de Agronomia de la Universidad del Zulia, v.22, n.4, p.315-323, 2005.

MIGUEL, E.G.; FERREIRA, L.R.; DONEGA, M.A.; DIASARIEIRA, C.R.; AVILA, M.R. Atividade de extratos de nim (Azadirachta indica) sobre o crescimento de Colletotrichum spp.. Summa Phytopathologica, v.32, p.S.18, 2006. Suplemento. Trabalho apresentado no CONGRESSO PAULISTA DE FITOPATOLOGIA, 29., 2006, Botucatu. Resumos. Botucatu, 2006. Resumo 034.

NELLY, D. Laboratory and greenhouse procedures methods for evaluation fungicides, nematicides and bactericides. Minessota: American Phytophathological Society, 1978. 140p.

PASSOS, F.A. Melhoramento do morangueiro no Instituto Agronômico de Campinas. In: DUARTE FILHO, J.; CANÇADO, G.M.A.; REGINA, M.A.; ANTUNES, L.E.C.; FADINI, M.A.M. (Ed.). Morango: tecnologia de produção e processamento. Caldas: EPAMIG, 1999. p.259-264.

PINTO, C.M.F.; MAFFIA, L.A.; CASALI, V.W.D.; CARDOSO, A.A. In vitro effect of plant feaf extracts on micelial growth and sclerotium germination of Sclerotium cepivorum. Journal of Phytophtthology, v.145, n.8/9, p.421-425, 1998.

RIBEIRO, L.F.; BEDENDO, I.P. Efeito inibitório de extratos vegetais sobre Colletotrichum gloeosporioides agente causal da podridão de frutos de mamoeiro. Scientia Agricola, v.56, n.4, p.1267-1271, 1999.

SCHWAN-ESTRADA, K.R.F.; STANGARLIN, J.R.; CRUZ, M.E.S. Uso de plantas medicinais no controle de doenças de plantas. Fitopatologia Brasileira, v.28, p.54-56, 2003. Suplemento. Trabalho apresentado no CONGRESSO BRASILEIRO DE FITOPATOLOGIA, 36., 2003, Uberlândia.

TANAKA, M.A.S.; PASSOS, F.A. Caracterização cultural e morfológica de isolados de Colletotrichum causadores de antracnose do morangueiro em São Paulo. Summa Phytophathologica, v. 24, n.2, p.145-151, 1998.

TANAKA, M.A.S.; BETTI, J.A.; KIMATI, H. Doenças do morangueiro-Fragaria $x$ ananassa Duch. In: KIMATI, $\mathrm{H}$.; AMORIN, L.; REZENDE, J.A.; BERGAMIN FILHO, A.; CAMARGO, L.E.A. (Ed.). Manual de fitopatologia: doenças das plantas cultivadas. 4.ed. São Paulo: Agronômica Ceres, 2005. v.2, p.489-499.

TELLO MARQUINA, J.C.; VEGA, J.D.M. Enfermedades no víricas del tomate. In: NUEZ, F. (Coord). El cultivo del tomate. Madrid: Ediciones Mundi-Prensa, 1995. p.523-563.

TROMBETA, D.; CASTELLI,F.; SARPIETRO, M.G.; VENUTI, V.; CRISTANI, M.; DANIELE, C.; SIJA, A.; MAZZANTI, G.; BISIGNANANO, G. Mechanisms of antibacterial action of three monoterpenes. Antimicrobial Agents and Chemotherapy, v.49, n.6, p.2474-2478, 2005.

VALARINI, J.P.; FRIGUETTO, R.T.S.; MELO, I.S. Potencial da erva medicinal Cymbopogum citratus (capim-limão) no controle de fitopatógenos do feijoeiro. Revista de Agricultura, v.69, p.139-150, 1994.

VALE, F.X.R.; ZAMBOLIM, L.; PAUL, P.A.; COSTA, H. Doenças causadas por fungos em tomate. In: ZAMBOLIM, L.,; VALE, F.X.R.; COSTA, H. (Ed.). Controle de doenças de plantas - hortaliça. Viçosa: UFV, 2000. p.699-755.

ZAMBOLIM, L.; COSTA, H.; VALE, F.X.R. Situação atual do controle químico de doenças de hortaliças. Horticultura Brasileira, v.18, p.96-110, 2000. Suplemento. Trabalho apresentado no CONGRESSO BRASILEIRO DE OLERICULTURA, 40., 2000, Campinas.

Recebido em $7 / 8 / 08$

Aceito em 7/10/09 